(c) American Dairy Science Association, 2005.

\title{
Short Communication: Amino Acids Antagonistic to the Amino Acids Inhibitory for Growth Rate of Mixed Ruminal Bacteria
}

\author{
H. Kajikawa, M. Mitsumori, K. Tajima, and M. Kurihara \\ National Institute of Livestock and Grassland Science, Tsukuba, Ibaraki 305-0901, Japan
}

\section{ABSTRACT}

Antagonism of some amino acids (AA) to the inhibitory effects of other AA (Ile, Phe, and Thr) on the growth rate of mixed ruminal bacteria was investigated. In vitro growth rate of the mixed ruminal bacteria was inhibited when the 3 inhibitory AA ( $1 \mathrm{~m} M$ each) were each added to individual control treatments in which an ammonium salt was included as a sole $\mathrm{N}$ source. The inhibitory effect caused by Ile was relieved by addition of Leu or Val (equimolar to Ile), and no significant inhibition was shown when both Leu and Val were added together with Ile. The growth inhibition caused by Phe was also alleviated by supplementing with Trp, and was completely negated by adding Tyr. The inhibitory effect of Thr, on the other hand, was not affected by addition of Lys or Met (which are synthesized using a common pathway with Thr), but was mitigated by supplementation with Glu, Ser, Val, Ala, or Gln. Among the antagonistic AA, Leu, Val, Trp, Tyr, and Glu were indispensable for the maximum growth rate of the ruminal bacteria under the experimental condition of supplementation of amino-N, the removal of which from a mixture of 20 protein AA caused the growth rate to decline. Removals of Ile along with Leu or Val or both, of Phe along with Trp or Tyr, and of Thr along with Glu recovered the promotion of bacterial growth rate. It was concluded that inhibitions of the bacterial growth rate caused by Ile, Phe, or Thr could be antagonized by some other AA (Leu, Val, Tyr, Trp, or Glu), and the role of these latter AA as relievers of the inhibitory effects could explain why they are indispensable for maximum growth rate of ruminal bacteria.

(Key words: rumen bacteria, amino acid, inhibition, antagonism)

Growth and fermentation rates of the ruminal bacteria can be improved by supplementation of amino-N (Van Kessel and Russell, 1996; Atasoglu et al., 1999),

Received June 30, 2004.

Accepted April 8, 2005.

Corresponding author: Hiroshi Kajikawa; e-mail: kajikawa@affrc. although most ruminal bacteria can grow with nonprotein $\mathrm{N}$ as their sole $\mathrm{N}$ source (Bryant and Robinson, 1962). On the contrary, our previous study (Kajikawa et al., 2002) found inhibitory effects exhibited by addition of some AA (Ile, Phe, and Thr in particular) on the growth rate of mixed ruminal bacteria. One of the most feasible explanations for such inhibition would be feedback inhibition of an early enzyme in the synthetic pathway of the AA; this inhibition also suppresses the production of other AA that use a common enzyme for their syntheses (Umbarger, 1956; De Felice et al., 1979). In this case, the latter AA could function antagonistically to the inhibitory AA, and a supply of them would allow the microbial growth that an inhibitory AA suppresses to recover. Our previous study also showed that the stimulation of bacterial growth with a mixture of $20 \mathrm{AA}$ was decreased by removing some AA individually from the mixture (Kajikawa et al., 2002). An explanation for the indispensability of these AA may be that if one of these AA is also an antagonistic AA, it acts as an alleviator of some inhibitory AA. The objectives of the current study were to investigate the presence of antagonistic AA and their effect on the inhibitory AA (i.e., Ile, Phe, and Thr) in terms of bacterial growth rate, and to investigate the indispensability of the antagonistic AA for stimulating bacterial growth rate in the presence or absence of the inhibitory AA.

Liquid and solid portions of the ruminal content were obtained before morning feeding from a ruminally fistulated nonlactating Holstein cow (560 kg BW) eating a diet consisting of timothy hay (67\% on DM), steamrolled corn grain (20\%), and soybean meal (13\%) twice a day (3.0 kg of DM per meal). The experiment continued for 3 mo after a 2 -wk period of adjustment of the ration. The experimental conditions were approved by the Animal Care Committee of the National Institute of Livestock and Grassland Science, Japan. Mixed ruminal bacteria were anaerobically harvested from the ruminal content as described previously (Kajikawa et al., 2002). The bacterial inoculum was diluted 20 times, thereby attaining an optical density (at $600 \mathrm{~nm}$ ) of 0.15 , into a growth medium containing the same amounts of minerals, vitamins, and VFA (acetic acid, isobutyric acid, valeric acid, isovaleric acid, and DL-2-metylbutyric 
acid) as described by Van Kessel and Russell (1996). The mixed bacteria were anaerobically incubated at $39^{\circ} \mathrm{C}$ with $4 \mathrm{~m} M$ glucose, $4 \mathrm{~m} M$ xylose, and $2 \mathrm{~m} M$ cellobiose. For the $\mathrm{NH}_{3}$-only treatment, $3.57 \mathrm{mM}$ (i.e., $100 \mathrm{mg}$ of N/L) of ammonium sulfate was added as a sole $\mathrm{N}$ source. For the AA treatments, various amounts $(0.1$ to $1.0 \mathrm{~m} M$ ) of AA were isonitrogenously replaced with ammonia in the $\mathrm{NH}_{3}$-only treatment. The growth rate was measured during the exponential growth phase. In the statistical model applied, the sum of the overall mean, the main effect of $\mathrm{N}$ source, and residual error are described. Growth rates of the mixed ruminal bacteria on each $\mathrm{N}$ source were measured in triplicate on different occasions. Treatments with different $\mathrm{N}$ sources were analyzed with 1-way ANOVA using the GLM procedure (SAS Institute, 1988). When an $F$-test detected a significant difference $(P<0.05)$, the significance of the difference between the treatment means was determined by Tukey's method using the studentized $t$-table $(P<0.05$ or 0.01$)$.

Table 1 shows the inhibition of the bacterial growth rate by the 3 inhibitory AA (1.0 $\mathrm{m} M$ of Ile, Phe, and Thr) in the absence or presence of an equimolar amount of other protein AA. For Ile, which showed $61 \%$ inhibition without any other AA, the inhibitory effect was significantly alleviated by addition of each of the other branched-chain AA. Although some inhibition by Ile remained when Leu or Val was added singly, significant inhibition disappeared when Leu and Val were supplemented together. No other AA had a significant effect on inhibition by Ile. Phenylalanine inhibited $48 \%$ of the bacterial growth rate when added singly, but addition of other aromatic AA (Trp and Tyr) alleviated the inhibition; in particular, an equimolar amount of Tyr completely negated the inhibitory effect of Phe. A lower level of Tyr $(0.1 \mathrm{mM})$ could also alleviate the inhibition by Phe more than $80 \%$ (data not shown). These findings suggest that the inhibition of the bacterial growth rate by Ile and Phe was caused by a feedback inhibition of an enzyme common for the synthesis of other AA because the other AA in the same group (branched-chain or aromatic group) antagonized their inhibitions. The reductive carboxylation reaction from branched-chain fatty acids to branched-chain AA has been reported in some ruminal anaerobes (Allison, 1969), and it is possibly considered that the presence of this reaction could be prevent the growth of the ruminal bacteria from a complete inhibition by supplementing Ile. Threonine effected a 50\% inhibition of the bacterial growth rate when supplemented singly, but addition of Glu, Ser, Val, Ala, or Gln mitigated the inhibition by 96,87 , 76,71 , and $50 \%$, respectively. The inhibition of growth rate by Thr appeared to be induced by some mechanism
Table 1. Inhibition of bacterial growth rate by inhibitory amino acids ${ }^{1}$ Ile, Phe, and Thr, as affected by the presence of other amino acids.

\begin{tabular}{lccc}
\hline & \multicolumn{3}{c}{ Inhibition of growth rate $^{2}(\%)$} \\
\cline { 2 - 4 } Additional $^{2}$ present & Ile & Phe & Thr \\
\hline None & 61 & 48 & 50 \\
Ala & 63 & 49 & $15^{\mathrm{a}, \mathrm{B}}$ \\
Arg & 61 & 47 & 45 \\
Asn & 63 & 48 & 46 \\
Asp & 64 & 48 & 44 \\
Cys & 58 & 45 & 57 \\
Gln & 60 & 46 & $25^{\mathrm{b}}$ \\
Glu & 57 & 47 & $2^{\mathrm{a}, \mathrm{B}}$ \\
Gly & 64 & 50 & 58 \\
His & 61 & 62 & 55 \\
Ile & - & 48 & 62 \\
Leu & $34^{\mathrm{B}}$ & 46 & 36 \\
Lys & 61 & 47 & 50 \\
Met & 59 & - & 40 \\
Phe & 59 & 49 & 51 \\
Pro & 64 & 48 & 47 \\
Ser & 61 & $35^{\mathrm{B}}$ & $7^{\mathrm{a}, \mathrm{B}}$ \\
Thr & 65 & $-1^{\mathrm{a}, \mathrm{B}}$ & 53 \\
Trp & 62 & 49 & 48 \\
Tyr & 64 & & $12^{\mathrm{a}, \mathrm{B}}$ \\
Val & $47^{\mathrm{b}}$ & $-3^{\mathrm{a}, \mathrm{B}}$ & 56 \\
Leu + Val & $10^{\mathrm{a}, \mathrm{B}}$ & 2 & 4 \\
Lys + Met & & & \\
Trp + Tyr & 2 & & \\
Pooled SE & & & \\
\hline
\end{tabular}

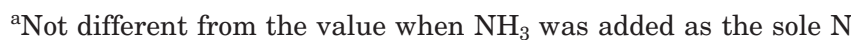
source $(P>0.05)$

${ }^{b, B}$ Significantly lower than the "None" value in the same column $(P<0.05$ and 0.01 , respectively).

${ }^{1}$ Supplemented at $1 \mathrm{~m} M$; Each "None" value showed significant inhibition $(P<0.01)$.

${ }^{2}$ Inhibition (\%) in the growth rate compared with the value when $\mathrm{NH}_{3}$ was added as the sole $\mathrm{N}$ source $(=0 \%)$; no growth $=100 \%$ inhibition.

${ }^{3}$ Supplemented at $0.5 \mathrm{mM}$ each when 2 AA were combined, or 1 $\mathrm{m} M$ otherwise. These AA were added along with the inhibitory AA noted.

other than feedback inhibition because an addition of Lys and Met did not affect the inhibition by Thr.

A provision of 20 protein AA promoted the growth rate of the mixed ruminal bacteria by $47 \%$ compared with the value when $\mathrm{NH}_{3}$ was added as the only $\mathrm{N}$ source (Table 2). Removal of Leu or Val, or both, from the 20 AA negated the stimulation by the AA mixture, but depletion of Ile at the same time recovered again the stimulation of the growth rate. Depletion of Trp or Tyr also dissipated the promotion of the bacterial growth rate exhibited by the addition of the AA mixture, but the stimulatory effect of amino-N on the growth rate recovered when Phe was removed together with Trp or Tyr. The stimulation of the bacterial growth rate, however, could not be recovered when Phe was depleted along with both Trp and Tyr. The presence of at least some aromatic AA seems to be essential for the growth stimulation by amino-N, presumably because a 
Table 2. Effect of absence of the inhibitory amino acids on indispensability of some antagonistic amino acids for improving the bacterial growth rate.

\begin{tabular}{|c|c|c|c|c|c|}
\hline \multirow{2}{*}{$\mathrm{N}$ source } & & \multirow{2}{*}{$\begin{array}{l}\text { Growth } \\
\text { rate }(/ \mathrm{h})\end{array}$} & \multicolumn{2}{|c|}{ Significance $^{1}$} & \multirow[b]{2}{*}{$>\mathrm{NH}_{3}$} \\
\hline & & & $<\mathrm{NH}_{3}$ & $<20 \mathrm{AA}$ & \\
\hline \multirow{3}{*}{\multicolumn{2}{|c|}{$\begin{array}{l}\mathrm{NH}_{3} \text { only } \\
20 \text { amino acids } \\
\text { Removed amino acid }\end{array}$}} & 0.309 & \multirow[t]{4}{*}{-} & \multirow{4}{*}{ ** } & \multirow{4}{*}{$\overline{* *}$} \\
\hline & & 0.455 & & & \\
\hline & & & & & \\
\hline Antagonistic & Inhibitory & & & & \\
\hline Leu & - & 0.262 & & $* *$ & \\
\hline Leu & Ile & 0.435 & & & $* *$ \\
\hline Val & - & 0.350 & & $* *$ & \\
\hline Val & Ile & 0.402 & & & $*$ \\
\hline Leu, Val & - & 0.198 & $* *$ & $* *$ & \\
\hline Leu, Val & Ile & 0.412 & & & $* *$ \\
\hline $\operatorname{Trp}$ & - & 0.355 & & $* *$ & \\
\hline Trp & Phe & 0.400 & & & $*$ \\
\hline Tyr & - & 0.235 & & $* *$ & \\
\hline Tyr & Phe & 0.416 & & & $* *$ \\
\hline Trp, Tyr & - & 0.200 & $* *$ & $* *$ & \\
\hline Trp, Tyr & Phe & 0.328 & & $* *$ & \\
\hline Glu & - & 0.341 & & $* *$ & \\
\hline Glu & Thr & 0.396 & & & * \\
\hline Pooled SE & & 0.015 & & & \\
\hline
\end{tabular}

${ }^{1}$ Significance: $<\mathrm{NH}_{3}$ and $<20 \mathrm{AA}=$ significantly lower than the values with $\mathrm{NH}_{3}$ only and $20 \mathrm{AA}$ as the $\mathrm{N}$ sources, respectively; $>\mathrm{NH}_{3}=$ significantly higher than the values with $\mathrm{NH}_{3}$ as only $\mathrm{N}$ source.

${ }^{2}$ The removed amino acid was removed from $20 \mathrm{AA}$ (each AA at 0.2 $\mathrm{m} M$ each).

$* P<0.05 ; * * P<0.01$.

depletion of these AA burdens the ruminal bacteria with some energy costs for synthesizing benzene rings (Sauer et al., 1975). Absence of Glu in the AA mixture also exhibited a decline of the stimulating effect, but its removal simultaneously with that of Thr also showed a recovery of growth stimulation. These AA, Leu, Val, Trp, Tyr, and Glu, act at the same time as antagonistic AA against the inhibition by the inhibitory AA. The role they play as a reliever of the inhibition is considered the major reason why these AA are essential for maximal growth of ruminal bacteria, based on the finding that the indispensability of these AA on the growth rate was in most cases eliminated by removal of the group of corresponding inhibitory AA.

The results of this study suggest that inhibitions exhibited by the inhibitory amino acids are mainly caused by feedback inhibition of the synthetic pathway of the analogous amino acids, not by inhibition of amino acid transport or other extracellular processes. Although it is likely that peptide transports are quantitatively more significant than amino acid transports for the ruminal bacteria in many situations of feeding ordinary rations (Wallace et al., 1997), it is possible that inhibition also occurs if incorporated peptides, which are degraded to amino acids in the bacterial cells, are abundant with the inhibitory amino acids. The stimulatory effect of amino-N on bacterial growth efficiency is applied in the Cornell Net Carbohydrate and Protein System (Russell et al., 1992), but the system does not differentiate the effect among individual AA. Consideration of the inhibitory effects of some AA and the antagonism of other AA to these inhibitions may improve the precision for estimating the amount of microbial yield and metabolizable protein in such a nutritional model.

\section{REFERENCES}

Allison, M. J. 1969. Biosynthesis of amino acids by ruminal microorganisms. J. Anim. Sci. 29:797-807.

Atasoglu, C., C. Valdés, C. J. Newbold, and R. J. Wallace. 1999. Influence of peptides and amino acids on fermentation rate and de novo synthesis of amino acids by mixed micro-organisms from the sheep rumen. Br. J. Nutr. 81:307-314.

Bryant, M. P., and I. M. Robinson. 1962. Some nutritional characteristics of predominant culturable ruminal bacteria. J. Bacteriol. 84:605-614.

De Felice, M., M. Levinthal, M. Iaccarino, and J. Guardiola. 1979. Growth inhibition as a consequence of antagonism between related amino acids: Effect of valine in Escherichia coli. Microbiol. Rev. 43:42-58.

Kajikawa, H., M. Mitsumori, and S. Ohmomo. 2002. Stimulatory and inhibitory effects of protein amino acids on growth rate and efficiency of mixed ruminal bacteria. J. Dairy Sci. 85:2015-2022.

Russell, J. B., J. D. O'Connor, D. G. Fox, P. J. Van Soest, and C. J. Sniffen. 1992. A net carbohydrate and protein system for evaluating cattle diets: I. Ruminal fermentation. J. Anim. Sci. 70:3551-3561

SAS Institute. 1988. SAS User's Guide. Statistics, Version 6.03. SAS Inst., Inc., Cary, NC.

Sauer, F. D., J. D. Erfle, and S. Mahadevan. 1975. Amino acid biosynthesis in mixed rumen cultures. Biochem. J. 150:357-372.

Umbarger, H. J. 1956. Evidence for a negative-feedback mechanism in the biosynthesis of isoleucine. Science 123:848.

Van Kessel, J. S., and J. B. Russell. 1996. The effect of amino nitrogen on the energetics of ruminal bacteria and its impact on energy spilling. J. Dairy Sci. 79:1237-1243.

Wallace, R. J., R. Onodera, and M. A. Cotta. 1997. Metabolism of nitrogen-containing compounds. Pages $283-328$ in The Rumen Microbial Ecosystem. 2nd ed. P. N. Hobson and C. S. Stewart, ed. Blackie Academic \& Professional, London, UK. 